\title{
ADIÇÃO DE COMPOSTOS ORGÂNICOS EM SUBSTRATO COMERCIAL PARA PRODUÇÃO DE MUDAS DE TOMATE
}

Rogério Nunes Gonçalves', Tiago Rodrigues de Sousa ${ }^{1}$, Marina da Costa Guerrero', Daniela Gonçalves Rosa', Gisele Carneiro da Silva ${ }^{2}$, Itamar Rosa Teixeira'

${ }^{1}$ Universidade Estadual de Goiás - UEG, Campus Ipameri, GO. ${ }^{2}$ Universidade Estadual de Goiás - UEG, Campus Posse, GO. E-mail: rogerionunes mvp@yahoo.com.br

\section{RESUMO}

Objetivou-se avaliar a formação de mudas de tomate cv. Santa Cruz Kada (Paulista) com incorporação de compostos orgânicos em distintas proporções no substrato comercial. Empregou-se o delineamento inteiramente casualizados, com quatro repetições. Os tratamentos foram constituídos das combinações: T1-substrato comercial; T2-substrato comercial+torta de mamona 2,5\%; T3-substrato comercial+torta de mamona 5,0\%; T4-substrato comercial+esterco de bovino 20,0\%; T5-substrato comercial+esterco de bovino 25,0\%; T6-substrato comercial+cama de aviário 10,0\% e T7-substrato comercial+cama de aviário $15,0 \%$. A mistura contendo $75 \%$ de substrato comercial com $25 \%$ de esterco de bovino possibilitou a produção de mudas de tomate de melhor qualidade.

Palavras-chave: Solanum lycopersicum L.; hortaliça; nutrição mineral; esterco; torta de mamona.

\section{ADDITION OF ORGANIC COMPOUNDS ON A SUBSTRATE FOR TOMATO SEEDLINGS}

\begin{abstract}
This study aimed to evaluate the formation of tomato seedlings cv. Santa Cruz Kada (Paulista) with the merger in the commercial substrate of organic compounds in different proportions. The design was a completely randomized design, with four replications. The treatments were formed from the combination of the mixture of commercial substrate with castor cake, cattle manure and aviary bed. Regarding the treatments, which presented averages significantly superior to the other was the mixture of $25 \%$ cattle manure and $75 \%$ commercial substrate for the production of tomato seedlings.
\end{abstract}

Keywords: Solanum lycopersicum L.; vegetable; mineral nutrition; cattle manure; castor cake.

\section{INTRODUÇÃO}

A produção de mudas assume como uma das principais fases na produção de hortaliças e a sua elevada qualidade e vigor são requisitos fundamentais para o desenvolvimento da futura planta no campo (MESQUITA et al., 2012). A plântula bem formada tem maior probabilidade de resistir às condições adversas do estresse ao serem transplantadas e relacionado com 0 manejo da cultura ideal propicia ganhos de produtividades desejáveis (COSTA et al., 2013). A obtenção dessas mudas está diretamente ligada ao tipo de substrato empregado no sistema de produção destas.

O substrato é um insumo amplamente utilizado na produção de mudas (FREITAS et al., 2013). Devido ao espaço reduzido retarda o desenvolvimento radicular e conseqüentemente a absorção de nutrientes, interferindo na qualidade da muda a ser transplantada (BLANKET al., 2014). Nesse aspecto, no processo de obtenção do substrato deve-se buscar por substrato que apresente características físicoquímicas desejáveis, baixo custo, fácil aquisição, capacidade de troca catiônica, sem presença de fitopatógenos, porosidade, retenção de umidade e uniformidade (OLIVEIRA et al., 2014), e nutrientes disponíveis às plantas e de longa durabilidade (BARDIVIESSOET al., 2014).

Embora o enriquecimento de substratos com fertilizantes minerais de elevada solubilidade +promove imediata disponibilização de seus nutrientes para mudas, quando este enriquecimento é realizado com fertilizantes 
orgânicos ocorre disponibilização gradual dos nutrientes neles contidos e disponíveis as plantas (KASHEM et al., 2015). Desta forma, a incorporação destes substratos aumenta os teores de matéria orgânica, a capacidade de armazenamento de água, resultando em maior disponibilidade às plantas, e além de fornecer nutrientes ao longo da fase de muda, e desenvolvimento da plântula ou planta até o momento de realizar o transplantio.

Em estudo realizado por Costa et al. (2012) constatou-se que o enriquecimento do substrato à base de Plantmax $^{\circledast}+$ composto orgânico propiciou a obtenção de elevada qualidade de mudas de berinjela e maiores produtividades. Costa et al. (2015) verificaram que o substrato composto por vida verde ${ }^{\circledR}+$ ramas de mandioca + esterco bovino + esterco aviário propiciou melhor desempenho das cultivares de tomate cereja, com maiores médias de altura de planta, produtividade e produção de frutos por planta, em relação aos substratos compostos vida verde ${ }^{\circledR}$ + ramas de mandioca e ramas de mandioca + esterco bovino. Silva e Queiroz (2014) avaliaram a formação de mudas de alface utilizando diversos materiais para compor substratos, sendo a cama de suínos com base de maravalha (M), cama de suínos com base de palha de café $(C)$, húmus de minhoca $(\mathrm{H})$ e os substratos comerciais Nutriorg ${ }^{\circledR}$ (N) e Plantmax ${ }^{\circledR}(\mathrm{P})$, usando estes substratos puros e em várias misturas. Verificaram que 0 tratamento contendo a cama de suínos com base de maravalha (M) possibilitou a obtenção de melhores características para a formação de mudas de alface em bandejas de isopor de 128 células.

O uso de resíduos orgânicos, gerados pela atividade animal, como fonte de nutriente às plantas, tem se constituído em alternativa viável, em termos de preservação ambiental, fazendo com que se reduza de maneira significativa a aplicação dos adubos químicos, minimizando a contaminação do meio ambiente e garantindo o fornecimento de matéria-prima ao longo prazo e com baixo custo (SANTOS et al., 2010). Apesar da existência de alguns estudos referente à utilização de materiais orgânicos alternativos na composição de substratos para produção de mudas de tomateiro, torna-se e se faz necessários estudos em distintas condições edafoclimáticas, uma vez que materiais orgânicos são muito heterogêneos quanto à sua composição química, físicas e biológicas, sendo assim escassas as informações da utilização desses compostos na produção de mudas.

Assim, objetivou-se com a realização deste estudo avaliar a formação de mudas de tomateiro produzidas em substrato comercial enriquecido com diferentes fontes e proporções de compostos orgânicos.

\section{MATERIAL E MÉTODOS}

O experimento foi conduzido no mês de julho de 2013, em casa de vegetação localizada no Câmpus experimental da Universidade Estadual de Goiás, Ipameri-GO, na latitude de 17음 $42^{\prime} 58^{\prime \prime} \mathrm{S}$ e longitude de $48^{\circ} 08^{\prime} 40^{\prime \prime} \mathrm{O}$, e $790 \mathrm{~m}$ de altitude. O clima da região de acordo com a classificação de Köppen é definido como tropical semi-úmido (Aw), caracterizado como mesoclimático, regime pluviométrico tropical semi-úmido com estação seca bem definida e regime térmico quente (NIMER, 1979), com temperatura média anual de $22^{\circ} \mathrm{C}$ e precipitação de $1.610 \mathrm{~mm}$. No inverno, a temperatura diurna e noturna na região fica em torno 25 a 16 oC, respectivamente.

O delineamento utilizado foi inteiramente casualizado, com quatro repetições. Os tratamentos foram constituídos da misturas das seguintes fontes orgânicas adicionadas em distintas proporções em substrato comercial: T1substrato comercial; T2-substrato comercial+torta de mamona 2,5\%; T3-substrato comercial+torta de mamona 5,0\%; T4-substrato comercial+esterco bovino 20,0\%; T5-substrato comercial+esterco bovino 25,0\%; T6-substrato comercial+cama de aviário $10.0 \%$ e T7-substrato comercial+cama de aviário $15.0 \%$. As definições das proporções de substratos orgânicos adicionados ao substrato comercial foram feitas em função dos tratamentos testados por Kleinet al. (2009).

O substrato comercial Plantmax $\mathrm{HT}^{\circledR}$ (hortaliças) usado possui a seguinte constituição química: $\mathrm{pH}\left(\mathrm{H}_{2} \mathrm{O}\right)-5,9 ; \mathrm{CO}-5,8 \mathrm{~g} \mathrm{dm}^{-3} ; \mathrm{Al}^{+3}+\mathrm{H}-$ $0,40 \mathrm{cmol}_{\mathrm{c}} \mathrm{dm}^{-3} ; \mathrm{P}-680 \mathrm{mg} \mathrm{dm}^{-3} ; \mathrm{K}-2,90 \mathrm{cmol}_{\mathrm{c}}$ $\mathrm{dm}^{-3} ; \mathrm{Ca}-7,80 \mathrm{cmol}_{\mathrm{c}} \mathrm{dm}^{-3} ;$ CTC $-18,60 \mathrm{cmol}_{\mathrm{c}} \mathrm{dm}^{-}$ 3. A constituição química dos compostos orgânicos e da mistura substrato comercial com os compostos orgânicos são apresentados abaixo (Tabelas 1 e 2) 
Tabela 1. Constituição química dos compostos orgânicos sólidos estudados presentes na massa seca analisada

\begin{tabular}{|c|c|c|c|c|c|c|c|c|}
\hline \multirow[t]{2}{*}{ Adubos Orgânicos } & $\mathrm{C} / \mathrm{N}$ & $\begin{array}{l}\mathrm{pH} \\
\left(\mathrm{CaCl}_{2}\right)\end{array}$ & U & $\mathrm{CO}$ & $\mathrm{N}$ & $\mathrm{P}_{2} \mathrm{O}_{5}$ & $\mathrm{~K}_{2} \mathrm{O}$ & $\mathrm{Ca}$ \\
\hline & $\%$ & - & $\%$ & \multicolumn{5}{|c|}{ 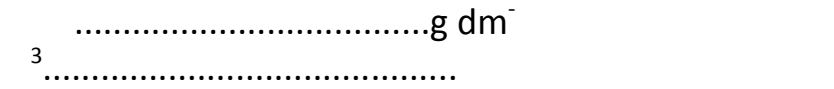 } \\
\hline Torta de mamona & 9 & 5.4 & 9 & 4,9 & 52 & 18 & 16 & 20 \\
\hline Esterco bovino curtido & 21 & 7.1 & 34 & 4,8 & 23 & 41 & 38 & 30 \\
\hline Cama de aviário & 22 & 8.2 & 28 & 4,8 & 22 & 24 & 27 & 23 \\
\hline \multirow{2}{*}{ Adubos Orgânicos } & $\mathrm{Mg}$ & $S$ & B & $\mathrm{Cu}$ & $\mathrm{Fe}$ & $\mathrm{Mn}$ & $\mathrm{Zn}$ & C.E \\
\hline & \multicolumn{2}{|c|}{$\ldots . \mathrm{g} \mathrm{dm}^{-3} \ldots}$. & & \multicolumn{4}{|l|}{$\mathrm{cm}^{-1}$} & $\mu S$ \\
\hline Torta de mamona & 9 & 2 & 30 & 80 & 1423 & 55 & 141 & 2.126 \\
\hline Esterco bovino curtido & 9 & 3 & 24 & 38 & 3512 & 335 & 329 & 916 \\
\hline Cama de aviário & 6 & 4 & 36 & 93 & 1300 & 302 & 228 & 6.060 \\
\hline
\end{tabular}

Tabela 2. Resultado da analise química das misturas do substrato comercial com compostos orgânicos sólidos em diferentes proporções

\begin{tabular}{|c|c|c|c|c|c|c|c|c|c|}
\hline \multirow{2}{*}{$\begin{array}{l}\text { Materiais } \\
\text { Orgânicos }\end{array}$} & $\begin{array}{c}\mathrm{pH} \\
\left(\mathrm{H}_{2} \mathrm{O}\right)\end{array}$ & $U$ & $\mathrm{CO}$ & $\mathrm{N}$ & $\mathrm{P}$ & K & $\mathrm{Ca}$ & $\mathrm{Mg}$ & $S$ \\
\hline & - & $\%$ & $\mathrm{~g} \mathrm{dm}^{-3}$ & \multicolumn{6}{|c|}{${ }_{1}$} \\
\hline S.C+T.M-2.5\% & 7,3 & 8,1 & 2,0 & 0,9 & 136,1 & $2.075,0$ & 220,0 & 165,0 & 200,0 \\
\hline S.C+T.M-5\% & 5,9 & 10,4 & 3,5 & $1.238,0$ & 225,0 & $1.670,0$ & 665,0 & 265,0 & 820,9 \\
\hline S.C+C.A-10\% & 6,1 & 17,9 & 5,1 & $2.0130,0$ & 328,0 & 545,0 & $1.310,0$ & 635,0 & $1.147,8$ \\
\hline S.C+C.A-15\% & 6,3 & 11,1 & 26,3 & $1.166,0$ & 279,0 & 550,0 & 960,0 & 510,0 & 903,0 \\
\hline S.C+E.B-20\% & 5,5 & 31,6 & 21,5 & $2.433,0$ & 264,0 & $1.125,0$ & $1.680,0$ & 520,0 & $1.030,0$ \\
\hline S.C+E.B-25\% & 5,4 & 45,7 & 14,7 & $4.941,0$ & 451,4 & $1.900,0$ & $1.885,0$ & 805,0 & 788,0 \\
\hline \multirow{2}{*}{$\begin{array}{l}\text { Materiais } \\
\text { Orgânicos }\end{array}$} & B & $\mathrm{Cu}$ & $\mathrm{Mn}$ & $\mathrm{Zn}$ & $\mathrm{Fe}$ & $\mathrm{NH}_{4}^{+}$ & $\mathrm{NO}_{3}^{-}$ & $\mathrm{C} / \mathrm{N}$ & $\mathrm{CE}$ \\
\hline & \multicolumn{7}{|c|}{ (1) } & $\ldots . . . \ldots$ & $\begin{array}{l}. \mu \mathrm{Cm}^{-} \\
1 .\end{array}$ \\
\hline S.C+T.M-2.5\% & 2,6 & 0,2 & 0,3 & 1,0 & 0,8 & 112,0 & $2.250,0$ & 2,3 & 1.012 \\
\hline S.C+T.M-5\% & 3,3 & 0,4 & 4,6 & 1,0 & 1,8 & 112,0 & $2.855,0$ & 0,3 & 1.521 \\
\hline S.C+C.A-10\% & 5,7 & 0,5 & 1,2 & 3,0 & 4,5 & 105,0 & 173,0 & 2,4 & 890 \\
\hline S.C+C.A-15\% & 2,7 & 0,1 & 1,4 & 2,0 & 1,9 & 63,0 & 221,0 & 226,0 & 990 \\
\hline S.C+E.B-20\% & 2,0 & 0,1 & 3,1 & 4,0 & 4,4 & 63,0 & 494,0 & 89,0 & 1.463 \\
\hline S.C+E.B-25\% & 3,7 & 0,1 & 0,9 & 2,0 & 4,2 & 91,0 & $1.036,0$ & 30,0 & 2.034 \\
\hline
\end{tabular}

(S.C) substrato comercial, (T.M) torta de mamona, (C.A) cama de aviário, (E.B) esterco bovino, (v/v) volume/ volume. 
As misturas contendo 0 substrato comercial e os compostos orgânicos foram usadas para preenchimento de bandejas de poliestireno expandido (isopor), com 128 células. Posteriormente efetuou-se a semeadura do tomateiro cv. Santa Cruz Kada (Paulista), colocando quatro sementes por célula, seguido de recobrimento de uma fina camada da mistura do substrato comercial. No quarto dia após a emergência efetuou-se o desbaste com auxílio de tesoura, deixando uma plântula por célula.

Foi realizada a irrigação com turno de rega fixo, cujo volume de água aplicado foi de $150 \mathrm{~mL}$ por parcela diariamente, mantendo o substrato próximo á capacidade de campo. Esta foi determinada com base na temperatura do ar e umidade relativa do ar, no interior do ambiente, perfazendo assim, os turnos de rega e volume adequado de água, a fim de manter umidade ao substrato e adequado as plântulas.

Para a análise do desenvolvimento das mudas de tomate, a parcela experimental consistiu em 32 células, porém, com área útil formada pelas 12 células centrais. Aos 28 dias após a semeadura (DAS) as plântulas foram colhidas inteiras apresentando $10-15 \mathrm{~cm}$ de altura e duas folhas definitivas e desmembradas em parte aérea e a raiz. Contabilizou-se o número de folhas por planta (NF), diâmetro de coleto (DC), altura da parte aérea (APA), as massas fresca e seca da parte aérea (MFPA) e (MSPA) e do sistema radicular (MFR) e (MSR) e total da planta (MST). A secagem da fitomassa foi realizada em estufa com circulação forçada de ar, a $65^{\circ} \mathrm{C}$ até massa constante. Somaram-se as MSPA e MSR para obtenção da fitomassa seca total (MST). Foram de terminadas as relações entre as fitomassas secas da parte aérea e raiz (RMS), a relação entre a altura e diâmetro do coleto (RAD), a relação entre a altura e fitomassa seca da parte aérea (RAM) e o índice de qualidade de Dickson (IQD), em que IQD= [MST/(RAD + RMS)].

Os dados foram submetidos à análise de variância pelo teste $F$, e as médias comparadas pelo teste de Tukey $(p<0,05)$ (FERREIRA et al., 2006).

\section{RESULTADOS E DISCUSSÃO}

As utilizações das diferentes tipos de compostos orgânicos sólidos incorporados em distintas proporções ao substrato comercial influenciaram no crescimento das mudas de tomate. O tratamento esterco bovino $25 \%$ adicionado ao substrato comercial apresentou o maior valor na variável número de folhas (NF) com 7,0 folhas planta ${ }^{-1}$ (Tabela 3). Isto possivelmente esta relacionado à maior disponibilidade de nitrogênio propiciado pela referida mistura, promovendo maior acumulo de biomassa pela planta, além de melhora as condições físicas do substrato devido a maior retenção umidade (Tabela 2 ).

As medidas de maior diâmetro do coleto (DC) de planta foram obtidos nos tratamentos esterco bovino $25 \%(2,87 \mathrm{~mm})$ e esterco bovino $20 \%$ $(2,81 \mathrm{~mm})$ adicionado ao substrato comercial, ao passo que, os compostos orgânicos torta de mamona $5 \%$ e cama de aviária $15 \%$ adicionados ao substrato comercial, propiciaram as menores médias para estas características, cujas médias respectivas foram de 1,87 e 1,89 $\mathrm{mm}$ (Tabela 3). Possivelmente, isso esta relacionado com a importância do balanço nutricional adequado na formação de mudas de tomateiro (Tabela 2).

Para a altura da parte aérea (APA) o tratamento com esterco bovino $25 \%$ ao substrato comercial, foi responsável pela maior média dentre os demais tratamentos - $13,8 \mathrm{~cm}$. Por outro lado, observou-se que o tratamento torta de mamona $2,5 \%$ proporcionou a menor APA $10,6 \mathrm{~cm}$, no entanto, não diferiu dos tratamentos substrato comercial puro $(11,3 \mathrm{~cm})$, cama de aviário $(11,6 \mathrm{~cm})$, esterco bovino $20 \%(12,0 \mathrm{~cm})$ e cama de aviário $15 \%(12,0 \mathrm{~cm})$ (Tabela 3). Considerando que o composto orgânico sólido esterco bovino $25 \%$ apresentou maiores teores dos nutrientes, sobretudo nitrogênio comparativamente aos demais compostos orgânicos sólidos (Tabela 2), este foi provavelmente o fator que proporcionou maior crescimento das mudas cultivadas com o referido composto. Para Luna et al. (2014), a fertilização com nitrogênio normalmente promove ganhos no crescimento, controlando o ritmo de crescimento, tamanho e vigor, visto que o nitrogênio é nutriente componente de proteínas e constituinte da molécula de clorofila, o que pode proporcionar maior produção de fotoassimilados, consequentemente maior acúmulo de biomassa.

Para a massa fresca da parte aérea (MFPA) de planta foi observado que o tratamento com esterco de bovino $25 \%$ adicionado ao substrato comercial correspondeu ao maior valor médio, com $0,74 \mathrm{~g}$ por planta. Os substratos orgânicos geralmente apresentaram teores mais elevados de nitrogênio, fósforo e potássio, quando 
comparados com o substrato comercial (Tabela 2), justificando assim o melhor desenvolvimento da parte aérea da planta promovido pela presença dos referidos nutrientes (Tabela 3 ), e que são requeridos pela planta em maior quantidade. Não obstante, os tratamentos cama de aviário $15 \%$ e torta de mamona 5\% incorporados ao substrato comercial apresentaram menores médias, com valores respectivos de 0,25 e 0,25 $\mathrm{g}_{\text {planta }}{ }^{-1}$ (Tabela 3 ). Possivelmente, isto possa estar relacionado ao desbalanço nutricional na formação das mudas do tomateiro, gerando pela menor disponibilidade de nutrientes nestas fontes orgânicos.

Para a característica massa fresca de raiz (MFR) de mudas de tomate, foi verificado que o tratamento esterco de bovino $25 \%$ acrescentado ao substrato comercial apresentou o maior valor, com 0,16 g por planta (Tabela 3). Este comportamento pode ser justificado pelo fato do substrato ser constituído de grande quantidade de macroporos, diante de sua maior incorporação em relação ao substrato comercial quando comparado aos demais compostos (Tabela 1). Além disso, a baixa densidade do material favorece o livre desenvolvimento das raízes, com poucas limitações.

Para a massa seca de raiz (MSR) foi observado que o tratamento que proporcionou maior produção de fitomassa foi esterco bovino $25 \%$ incorporado ao substrato comercial, correspondente a $0,08 \mathrm{~g}$ por planta (Tabela 1). Esse efeito pode estar associado à maior capacidade nutritiva no esterco de bovino associado à capacidade de retenção de água do substrato (Tabela 2), proporcionando maior acúmulo de massa seca pelas plantas e maior lignificação dos tecidos. Além disso, as mudas aproveitaram os nutrientes e a água existentes no composto de modo eficiente, pois houve conversão em massa seca.

Com relação a massa seca total (MST) de planta de tomate, o tratamento esterco de bovino $25 \%$ adicionado ao substrato comercial se destacou em relação aos demais por proporcionar a obtenção a $0,47 \mathrm{~g}$ por planta. Em contrapartida, os menores valores para a MST foram verificados nos tratamentos torta de mamona $5 \%$ e cama de aviário $15 \%$ adicionados ao substrato comercial, com valores de 0,15 e $0,14 \mathrm{~g}$ por planta respectivamente (Tabela 3 ). Possivelmente, as condições adequadas encontradas pelas plantas de tomateiro no substrato composto pela mistura de esterco bovino e substrato comercial está relacionado à boa aeração, disponibilidade de nutrientes e retenção de água, relatos concordantes aos resultados da pesquisa de Fernandes et al. (2006) com tomate cereja fertilizado com substratos distintos. Destaca-se que mistura de material orgânico para composição de substrato apresenta a vantagem de disponibilizar maior quantidade de nutrientes, além da retenção de maior quantidade de água favorecendo assim o desenvolvimento das plantas.

A razão entre a massa seca da parte aérea e radicular (RMS), assim como a relação altura da plântula e diâmetro do colo (RAD), apresentaram diferenças significativas entre os compostos orgânicos adicionado ao substrato comercial em distintas proporções. A média dos sete tratamentos foi de 5,82 para a razão entre a massa seca aérea e radicular (RMS) e de 5,20 para a relação entre altura da plântula e diâmetro do colo (RAD) (Tabela 4).

O crescimento adequado das mudas, com aumento proporcional entre altura e colo, ou seja, o aumento da altura da plântula foi acompanhado do aumento da espessura do colo, não caracterizando estiolamento das mesmas. Como não foi detectado estiolamento (RAD) e a distribuição entre as massas secas da parte aérea e radicular diferiu nos tratamentos, infere-se que as mudas apresentaram qualidade e vigor satisfatórios; no entanto, os tratamentos torta de mamona $5 \%$ e cama de aviário $15 \%$ incorporado ao substrato comercial apresentaram as piores resultados de RMS e RAD, respectivamente. Possivelmente, o resultado obtido esteja relacionado à limitação da disponibilidade de nutrientes presentes nessas misturas, relacionado aos teores elevados de nitrato e $\mathrm{pH}$.

A mistura de esterco bovino ao substrato comercial propiciou mudas de elevada qualidade, conforme os resultados de menor razão entre altura e massa seca da parte aérea (RAM) - 35,3 e o maior índice de qualidade de Dickson (IQD) 0,009 (Tabela 4). Assim, verificou-se que o substrato que continha em sua constituição o esterco bovino propiciou condições mais adequadas ao desenvolvimento das mudas.

As respostas diferenciada das plantas de tomate à adição de diferentes proporções de compostos orgânicos sólidos a substrato comercial podem ser devido à liberação de quantidades variável de nutrientes disponíveis nas misturas obtidas (substratos). Além disso, em 
termos de crescimento das plantas, composto orgânico sólido desempenha um papel importante na melhoria da textura do substrato, como aeração, compactação e, portanto, aumento na disponibilidade de água e absorção de nutrientes pelas plantas de seu meio circundante como as áreas da zona radicular. $\mathrm{O}$ substrato comercial propiciou provavelmente, baixo acumulo de biomassa, devido a menor quantidade de macronutrientes (nitrogênio, fósforo e potássio) e lixiviação destes nutrientes pela irrigação, possivelmente limitando o acumulo de biomassa.

Quanto à torta de mamona, a alta concentração de amônio, possivelmente, levou ao efeito tóxico ás raízes, ocasionando desequilíbrios nutricionais, reduzindo a absorção de cátions, limitando assim, o crescimento das plântulas de tomateiro. Já a cama de aviário, com pH próximo a neutro (Tabela 1), favorece a maior disponibilidade dos macronutrientes, mas ocasiona efeito negativo na absorção dos micronutrientes catiônicos, limitando assim, o acumulo de biomassa. Verificou-se que ambos os substratos que continham em sua constituição o esterco bovino, propiciaram condições mais adequadas ao desenvolvimento das plântulas de tomateiro. Ao ser adicionado em maior quantidade, propiciou, provavelmente, maior aceleração e degradação do resíduo orgânico presente no composto, favorecendo uma melhor disponibilidade dos nutrientes, permitindo assim, a obtenção de mudas de tomateiro mais vigorosas.

Em síntese, o substrato composto por esterco bovino mais substrato comercial PlantmaxHT ${ }^{\circledR}$ propiciou maior desenvolvimento das plântulas do tomateiro, na maioria das características avaliadas. Indicando a possibilidade de utilização deste composto orgânico, pois além de ser uma opção econômica que reduz custos de produção, é uma alternativa para a reciclagem e emprego de subprodutos da pecuária. $O$ que a caracteriza este composto como uma alternativa viável para a produção de mudas de tomate.

Tabela 3. Valores médios do número de folha (NF) por planta, diâmetro de coleto (DC), altura da parte aérea (APA), massas fresca da parte aérea (MFPA) e do sistema radicular (MFR), massas seca do sistema radicular (MSR) e da parte aérea (MSPA) e massa seca total (MST) de mudas de tomate em função da mistura de proporções distintas de compostos orgânicos com substrato comercial, aos 28 dias após semeadura

\begin{tabular}{|c|c|c|c|c|c|c|c|c|}
\hline Tratamentos & $\begin{array}{c}\mathrm{NF} \\
-\end{array}$ & $\begin{array}{c}\mathrm{DC} \\
(\mathrm{mm})\end{array}$ & $\begin{array}{l}\text { APA } \\
(\mathrm{cm})\end{array}$ & $\begin{array}{c}\text { MFPA } \\
\text { (g } \\
\text { planta }^{-1} \text { ) }\end{array}$ & $\begin{array}{c}\text { MFR } \\
\text { (g } \\
\text { planta }^{-1} \text { ) }\end{array}$ & $\begin{array}{c}\text { MSR } \\
\text { (g } \\
\text { planta }^{-1} \text { ) }\end{array}$ & $\begin{array}{c}\text { MSPA } \\
\text { (g } \\
\text { planta }^{-1} \text { ) }\end{array}$ & $\begin{array}{c}\text { MST } \\
\text { (g } \\
\text { planta }^{-1} \text { ) }\end{array}$ \\
\hline Sub. Com. & $4.37 c$ & $2.47 \mathrm{~b}$ & $11.25 \mathrm{~b}$ & $0.45 \mathrm{c}$ & $0.08 \mathrm{c}$ & $0.04 \mathrm{c}$ & $0.24 \mathrm{c}$ & $0.28 \mathrm{c}$ \\
\hline $\begin{array}{l}\text { Sub. Com. + Tor. } \\
\text { Mam. } 2.5 \%\end{array}$ & $5.00 \mathrm{c}$ & $2.26 \mathrm{c}$ & $10.60 \mathrm{~b}$ & $0.38 d$ & $0.06 \mathrm{~d}$ & $0.03 d$ & $0.20 \mathrm{~d}$ & $0.23 \mathrm{~d}$ \\
\hline $\begin{array}{l}\text { Sub. Com. + Tor. } \\
\text { Mam. } 5.0 \%\end{array}$ & $4.87 \mathrm{c}$ & $1.87 \mathrm{~d}$ & $12.99 \mathrm{~b}$ & $0.25 \mathrm{e}$ & $0.03 \mathrm{f}$ & $0.01 \mathrm{f}$ & $0.13 \mathrm{e}$ & $0.15 \mathrm{e}$ \\
\hline $\begin{array}{l}\text { Sub. Com. + E. Bov. } \\
20 \%\end{array}$ & $6.37 \mathrm{~b}$ & $2.81 \mathrm{a}$ & $11.99 \mathrm{~b}$ & $0.56 \mathrm{~b}$ & $0.11 \mathrm{~b}$ & $0.05 \mathrm{~b}$ & $0.29 \mathrm{~b}$ & $0.35 \mathrm{~b}$ \\
\hline $\begin{array}{l}\text { Sub. Com. + E. Bov. } \\
25 \%\end{array}$ & $7.00 \mathrm{a}$ & $2.87 \mathrm{a}$ & $13.81 \mathrm{a}$ & $0.74 \mathrm{a}$ & $0.16 \mathrm{a}$ & $0.08 \mathrm{a}$ & $0.39 \mathrm{a}$ & $0.47 \mathrm{a}$ \\
\hline $\begin{array}{l}\text { Sub. Com. + C. Av. } \\
10 \%\end{array}$ & $5.00 \mathrm{c}$ & $2.49 \mathrm{~b}$ & $11.64 \mathrm{~b}$ & $0.44 c$ & $0.08 \mathrm{c}$ & $0.04 \mathrm{c}$ & $0.23 \mathrm{c}$ & $0.28 \mathrm{c}$ \\
\hline $\begin{array}{l}\text { Sub. Com. + C. Av. } \\
15 \%\end{array}$ & $5.25 \mathrm{c}$ & $1.89 \mathrm{~d}$ & $12.02 \mathrm{~b}$ & $0.23 \mathrm{e}$ & $0.05 \mathrm{e}$ & $0.02 \mathrm{e}$ & $0.12 \mathrm{e}$ & $0.14 \mathrm{e}$ \\
\hline C.V. & 7.36 & 3.74 & 5.67 & 4.51 & 11.68 & 11.38 & 4.58 & 4.27 \\
\hline DMS & 0.93 & 0.21 & 1.59 & 0.04 & 0.02 & 0.01 & 0.02 & 0.03 \\
\hline
\end{tabular}

* Médias seguidas de mesma letra, na coluna, não diferem entre si, pelo teste de Tukey, a 5\% de probabilidade. (Sub. Com.) substrato comercial Plantmax $\mathrm{HT}^{\circledR}$, (Tor. Mam.) torta de mamona, (E. Bov.) esterco de bovino, (C. Av.) cama de aviário. 
TABELA 4. Razão massa seca (RMS), razão altura/ diâmetro (RAD), razão altura/ massa seca da parte aérea (RAM), índice de qualidade de Dickson (IQD), avaliadas aos 28 dias após semeadura de mudas de tomate, para diferentes proporções de compostos orgânicos em relação ao substrato comercial

\begin{tabular}{lcccc}
\hline Tratamentos & RMS(g) & RAD & RAM & IQD \\
\hline Sub. Com. & $5.44 \mathrm{~b}$ & $4.58 \mathrm{~b}$ & $47.39 \mathrm{~b}$ & $0.005 \mathrm{c}$ \\
Sub. Com. + Tor. Mam. 2.5\% & $5.91 \mathrm{~b}$ & $4.70 \mathrm{~b}$ & $53.05 \mathrm{~b}$ & $0.004 \mathrm{~d}$ \\
Sub. Com. + Tor. Mam. 5\% & $9.27 \mathrm{a}$ & $6.95 \mathrm{a}$ & $97.06 \mathrm{a}$ & $0.002 \mathrm{e}$ \\
Sub. Com. + E. Bov. 20\% & $5.30 \mathrm{~b}$ & $4.18 \mathrm{~b}$ & $40.71 \mathrm{c}$ & $0.007 \mathrm{~b}$ \\
Sub. Com. + E. Bov. 25\% & $4.71 \mathrm{~b}$ & $4.92 \mathrm{~b}$ & $35.26 \mathrm{c}$ & $0.009 \mathrm{a}$ \\
Sub. Com. + Cama Av. 10\% & $5.38 \mathrm{~b}$ & $4.68 \mathrm{~b}$ & $50.08 \mathrm{~b}$ & $0.005 \mathrm{c}$ \\
Sub. Com. + Cama Av. 15\% & $4.71 \mathrm{~b}$ & $6.37 \mathrm{a}$ & $100.77 \mathrm{a}$ & $0.002 \mathrm{e}$ \\
\hline C.V. & 22.04 & 7.44 & 9.31 & 9.050 \\
DMS & 2.99 & 9.04 & 13.19 & 0.001 \\
\hline
\end{tabular}

* Médias seguidas de mesma letra, na coluna, não diferem entre si, pelo teste de Tukey,a $5 \%$ de probabilidade. (Sub. Com.) substrato comercial, (Tor. Mam.) torta de mamona, (E. Bov.) esterco de bovino, (Cama Av.) cama de aviário.

\section{CONCLUSÃO}

O substrato constituído pela mistura de $25 \%$ de esterco de bovino e $75 \%$ de substrato comercial Plantmax $\mathrm{HT}^{\circledR}$ é o mais adequado para produção de mudas de tomate de qualidade.

\section{REFERÊNCIAS}

BARDIVIESSO, E. M.; COSTA, E.; BARCELOS, M. N.; BARDIVIESSO, D. M.; MURAKAMI, F. Crescimento de berinjela verde em diferentes substratos. Revista de agricultura neotropical, CassilândiaMS, v. 1, n. 1, p. 17-25, 2014.

BLANK, A. F.; ARRIGONI-BLANK, M. F.; CARVALHO FILHO, J. L. S.; SANTOS NETO, A. L.; AMANCIOLIMA, V. F. Produção de mudas de manjericão com diferentes tipos de Substratos e recipientes. Journal Bioscience, Uberlândia, v. 30, n. 1, p. 3944, 2014.

COSTA, E; SANTO, T. L. E.; SILVA, A. P.; SILVA, L. E.; OLIVEIRA, L. C.; BENETT, C. G. S.; BENETT, K. S. $S$. Ambientes e substratos na formação de mudas e produção de frutos de cultivares de tomate cereja. Horticultura Brasileira, v.33, n.1, p.110118, 2015. http://dx.doi.org/10.1590/S0102$\underline{053620150000100018}$

COSTA, E.; DUARTE, L. G. Y.; SANTOS, A. e FERREIRA, C. R. Production of eggplant from seedlings produced in different environments, containers and substrates. Horticultura Brasileira, Brasília, v. 31, n. 5, p. 139-146, 2013. http://dx.doi.org/10.1590/S0102$\underline{05362013000100022}$
COSTA, E.; PEgORARE, A. B.; LEAL, P. A. M.; ESPINDOLA, J. S.; SALAMENE, L. C. P. Formação de mudas e produção de frutos de berinjela. Científica, Jaboticabal, v. 40, n. 1, p. 12-20. 2012.

FERNANDES, C; CORÁ, J. E.; BRAZ, L. T. Desempenho de substratos no cultivo do tomateiro do grupo cereja. Horticultura Brasileira, v. 24, n.1, p. 42-46, 2006.

FERREIRA, D. F. SISVAR - Sistema de análise de variância. Versão 5. 3. Lavras - MG: UFLA. 2010.

FREITAS, G. A.; SILVA, R. R.; BARROS, H. B.; MELO. A. V.; ABRAHÃO, W. A. P. Produção de mudas de alface em função de diferentes combinações de substratos. Revista Ciência Agronômica, Fortaleza, v. 44, n. 1, p. 159-166, 2013.

KASHEM, M. A., SARKER, A., HOSSAIN, I.; ISLAM, M. S. Comparison of the effect of vermicompost and inorganic fertilizers on vegetative growth and fruit production of tomato (Solanum lycopersicum L.). Open Journal of Soil Science, v. 5, n. 2, p. 53-58, 2015. doi: 10.4236/ojss.2015.52006.

LUNA, A. M.; GARCÍA, E. R.; SERVÍN, J. L. C.; HERRERA, A. L.; ARELLANO, J. S. Evaluation of different concentrations of nitrogen for tomato seedling production (Lycopersicon esculentum Mill.). Universal Journal of Agricultural Research, Madri, v. 2, n. 8, p. 305-312, 2014. DOI: 10.13189/ujar.2014.020804

MESQUITA, E. F.; CHAVES, L. H. G.; FREITAS, B. V.; SILVA, G. A.; SOUSA, M. V. R.; ANDRADE, R. Produção de mudas de mamoeiro em função de 
substratos contendo esterco bovino e volumes de recipientes. Revista Brasileira de Ciências Agrárias, Recife, v.7, n. 1, p.58-65, 2012. DOI:10.5039/agraria.v7i1a1448

NIMER, E. Climatologia do Brasil. Superintendência dos Recursos Naturais e Meio Ambiente. Rio de Janeiro: Fundação Instituto Brasileiro de Geografia e Estatística, 1979. (Série Recursos Naturais e Meio Ambiente, IBG, n. 24)

OLIVEIRA, F. A.; MEDEIROS, J. F.; LINHARES, P. S. F.; ALVES, R. C.; MEDEIROS, A. M. A.; OLIVEIRA, M. K. T. Produção de mudas de pimenta fertirrigadas com diferentes soluções nutritivas. Horticultura Brasileira, v. 32, n. 4, p.458-463, $2014 . \quad$ http://dx.doi.org/10.1590/S0102053620140000400014.

SANTOS, M. R.; MARIA, A. N. S.;LUÍS, T. S.; SANZIO, M.V.; FELIPE R. Produção de mudas de pimentão em substratos à base de vermicomposto. Journal Bioscience. Uberlândia, v. 26, n. 4 , p. $572-578,2010$.

SILVA, E. C.; QUEIROZ, R. L. Formação de mudas de alface em bandejas preenchidas com diferentes substratos. Journal Bioscience. Uberlândia, v. 30, n. 3, p. 725-729, 2014.

Recebido para publicação em 07/02/2018

Revisado em 29/06/2018

Aceito em 13/08/2018 